\title{
A perversão dos ideais no fundamentalismo religioso*1
}

\author{
Zeferino Rocha*2
}

O objetivo do artigo é refletir, na perspectiva da metapsicologia freudiana, sobre alguns processos e componentes psíquicos de natureza perversa, que estão na base dos ideais dos fundamentalistas religiosos. Neste contexto, consideraremos o conceito de "narcisismo de morte" (ou "narcisismo negativo") e sua articulação com a pulsão de morte, como também a distinção entre Eu ideal e Ideal do Eu para melhor compreender o modelo das "idealizações", pelas quais os fundamentalistas religiosos sacrificam seu próprio Eu, em nome de um Eu ideal que não é senão a projeção de suas ambições narcísicas infantis.

Palavras-chave: Fundamentalismo religioso, perversão, narcisismo, Eu ideal e Ideal do Eu

*1 Trabalho apresentado no Colóquio Internacional sobre a Metapsicologia da Perversão, Laços Sociais da Perversão, realizado em Recife nos dias 26, 27 e 28 de agosto de 2013.

*2 Universidade Católica de Pernambuco - Unicap (Recife, PE, Br). 


\section{Introdução}

O problema do fundamentalismo religioso desafia nossa capacidade de compreensão e, como um verdadeiro enigma, sua significação nos escapa, quando nos esforçamos para decifrar seu segredo. Todavia, não obstante esta dimensão enigmática de sua natureza, o fundamentalismo religioso tem um lugar de destaque no cenário de nossa cultura contemporânea e sua atualidade é indubitável. Além disso, graças ao prodigioso desenvolvimento dos meios de comunicação tecnológica contemporânea, ele invade, com sua face de terror e de destruição, a intimidade de nossos lares e somos todos transformados em espectadores atônitos das cenas de terrorismo praticadas pelos seus adeptos.

\section{O contexto histórico e cultural do fundamentalismo religioso}

Para descrever as linhas essenciais deste contexto, vamos lembrar, brevemente, que um dos principais objetivos do Projeto Cultural da Modernidade se propunha a realizar aquilo que Max Weber denominou: "Die Entzauberung der Welt", vale dizer, o "Desencantamento do mundo". Para conseguir este objetivo, dois caminhos foram abertos: a dessacralização da Natureza e a criação de uma nova ordem de realidade, intrinsecamente lógica e estruturalmente regida pelas ciências matemáticas. A Natureza seria libertada do poder dos deuses, do medo das crendices e das superstições dos feiticeiros; ela deixaria de ser contemplada como o poema de Deus, para ser vista como um objeto de transformação para a razão técnica do homem moderno, cuja divisa não podia ser mais significativa: "saber para poder e saber para dominar".

Pois bem, como observa Marilena Chauí (2006), quando a Modernidade se propôs a realizar o "desencantamento do Mundo", ela deslocou a religião do espaço público, que ocupava desde a Idade Média, para o espaço privado das consciências individuais, destinando-a e condenando-a a desaparecer 
com o progresso da Ciência. A religião e o sagrado foram dispensados e atribuiu-se à ideologia a tarefa de cimentar a vida social e política.

Mas, o Projeto Cultural da Modernidade fracassou, e, hoje, nós vivemos as consequências deste fracasso. Os pensadores da Cultura falam de uma crise que mina os alicerces de nosso mundo contemporâneo. David Herwey (1992) resumiu os efeitos sociais e econômicos desta crise contemporânea, ressaltando a sua “compressão espacial e temporal". Para ele, há, em nosso mundo contemporâneo, uma fragmentação e dispersão do espaço e do tempo, que condicionam a sua reunificação em um espaço indiferenciado, em um tempo efêmero e, sobretudo, em uma visão de mundo, na qual não se pode contar com a dimensão do futuro, enquanto "possibilidade de determinação do indeterminado". Nesta experiência de fragmentação, nosso presente esgota-se na realidade de um instante fugaz. Semelhante situação leva-nos ao abandono de toda expectativa em relação ao possível, não nos restando outra saída que fazer o elogio da contingência e da incerteza essenciais.

Pois bem, este contexto, marcado pela contingência e pela efemeridade, criou um clima favorável para o retorno do fundamentalismo religioso, pois, apesar de ter renunciado às noções de eternidade e de necessidade, a visão de mundo do homem contemporâneo não deixou de procurar substitutos para essas noções. E elas reapareceram no fundamentalismo religioso, tanto na sua face religiosa quanto política, pois ele se engajou na construção de um imaginário, no qual as noções substitutas de necessidade e de eternidade foram fundamentadas em duas formas interligadas de transcendência: a transcendência divina da Palavra de Deus e a transcendência do poder político dos governos autoritários, como uma manifestação, no tempo, da vontade de Deus.

Compreende-se, assim, que a crise contemporânea provocada pelo fracasso do Projeto Cultural de Modernidade tenha favorecido o retorno da religião sob a forma do fundamentalismo religioso, não somente como uma experiência individual, mas também como uma interpretação da vida e da ação política. Por esta razão, igualmente, o fundamentalismo religioso desdobra-se, quase sempre, em um fundamentalismo político.

No entanto, este retorno é um retorno ameaçador. Marilena Chauí (2006) faz a seguinte ponderação: porque as religiões fundamentalistas acreditam estar em relação imediata com a vontade de Deus, enquanto portadoras da verdade eterna e universal, nelas não há lugar para a diferença e a figura do outro é olhada como se fosse a do demônio. O campo político transforma-se em um campo de batalha entre o Bem e o Mal e a autoridade política, como uma missão sagrada, é comandada pelo próprio Deus! A política cede lugar à violência como purificação do mal e os políticos passam a assumir o papel de profetas, chefes infalíveis, intérpretes da vontade divina. Que isto nos baste para descrever brevemente o contexto histórico e cultural do fundamentalismo religioso. 


\section{O fundamentalismo religioso}

Após esta breve introdução sobre o contexto histórico e cultural do fundamentalismo religioso, vou dizer, de modo bem simples, como o compreendo. Esta atitude se faz necessária porque, como sabemos, não existe uma só espécie de fundamentalismo religioso, nem mesmo uma só maneira de compreendê-lo. Há muitas. É preciso, portanto, que defina como o compreendo.

Vejo o fundamentalismo religioso como um modo de ser, de pensar e de agir, que resulta de uma crença e de uma adesão incondicionais a uma doutrina religiosa, qualquer que ela seja, judaica, cristã ou islâmica, considerando-a como a única detentora e protetora do Bem e da Verdade. E, em virtude desta atitude radical, os fundamentalistas religiosos tratam como inimigos todas as outras religiões e pessoas, que não comunguem com suas crenças, nem com seus ideais, tanto religiosos como políticos.

Os bárbaros são os outros. A Barbárie vem sempre de fora. Os bárbaros são todos aqueles que não são os membros de uma mesma religião, de um mesmo partido, de uma mesma pátria e assim por diante. Considerado desta forma, o fundamentalista religioso é um homem fanático e intransigente para com tudo o que é novo, ou diferente, de seu modo habitual de pensar e de agir.

O fundamentalista religioso (judaico, cristão ou islâmico) interpreta, literalmente, os Livros Sagrados, nos quais acredita encontrar a revelação da Vontade divina sobre todas as questões que dizem respeito ao seu modo de pensar e de agir, sem situá-los no seu contexto histórico e cultural e sem admitir que eles possam ser renovados, ou atualizados, para responder às exigências das transformações históricas e culturais que, espontaneamente, acompanham a marcha da História da Civilização Humana.

O fundamentalismo religioso e o fundamentalismo político estão frequentemente unidos porque, em última análise, são a consequência lógica de uma mesma ideologia e nós entendemos, aqui, por ideologia, a doutrina que possui uma resposta para todas as questões que são e serão, eventualmente, postas no decorrer dos acontecimentos e das dificuldades de nossa vida individual e social.

Assim consideradas, as doutrinas fundamentalistas, tanto religiosas como políticas, não são consideradas por seus adeptos como simples doutrinas, elas são dogmas irrefutáveis, contra os quais é inteiramente inútil querer argumentar, porque os fundamentalistas os aceitam não como uma conclusão baseada em uma convicção intelectual, nem pela força de uma argumentação puramente racional, mas por motivações afetivas, nutridas por mecanismos psíquicos cuja origem e motivação eles não podem conhecer, porque são inconscientes. Esta é a maneira, talvez simplificada demais, de como compreendo o fundamentalismo religioso. 


\section{ARTIGOS}

\section{Um olhar psicanalítico sobre o fundamentalismo religioso}

Depois de ter dito como entendo o fundamentalismo religioso, gostaria de apresentar, resumidamente, na perspectiva da metapsicologia freudiana, os mecanismos psíquicos que, segundo penso, estão na base dos ideais do fundamentalismo religioso, na esperança de que eles lancem um pouco de luz sobre o enigma de sua natureza, que, como já disse, desafia nossa capacidade de compreensão.

A psicanálise não tem uma explicação definitiva para decifrar o enigma da esfinge fundamentalista. No entanto, ela já nos terá prestado um grande serviço neste trabalho de compreensão, se nos oferecer alguns subsídios para identificar e compreender as raízes psíquicas, que estão na base da perversão dos ideais, bem como das fantasias e das idealizações, que dinamizam o modo de pensar e de agir dos fundamentalistas religiosos.

Levando em consideração o tempo de que disponho, vou restringir-me a recordar alguns conceitos psicanalíticos que poderão ajudar-nos a esclarecer um pouco as raízes psíquicas que se encontram na base da perversão dos ideais do fundamentalismo religioso. Antes de tudo, vou tentar mostrar como o modo de pensar e de agir dos fundamentalistas nos oferecem um belo exemplo daquilo que, na perspectiva psicanalítica, designa-se com o nome de "narcisismo de morte" ou de "narcisismo negativo".

\section{Narcisismo negativo}

André Green (1983) propôs a noção de "narcisismo negativo" para traduzir a contrapartida negativa do "narcisismo primário absoluto", no qual predomina a onipotência de uma plenitude imaginária e ilusória, da qual nos fala Freud em seu estudo de 1914, no qual introduziu o narcisismo no conjunto de sua metapsicologia.

Porque se tratava de um estado hipotético, no qual a libido era inteiramente investida no eu, como em um estado "primeiro" antes de qualquer investimento objetal, vários discípulos de Freud tiveram grande dificuldade de aceitar semelhante "estado anobjetal". Sem querer discutir, aqui, esta questão, direi apenas que, na minha opinião, as discussões se multiplicam por causa da perspectiva psicogenética, adotada por Freud, quando anunciou o "narcisismo primário".

No entanto, se olharmos o "narcisismo primário" não como um estado "primeiro" numa escala de desenvolvimento psicogenético, mas como uma "estrutura", então, na sua forma "originária" (ursprüngliche), ele poderia ser visto como "a condição de possibilidade" de toda vida libidinal e como fundamento da estruturação do sujeito, enquanto ser de desejo. De qualquer forma, este "investimento 
originário da libido no eu" (Freud, 1914/1982, Band III, p. 43) não é temporário, mas estruturante, pois continua mesmo depois do investimento da libido nos objetos.

No "narcisismo negativo", no lugar desta estruturação do sujeito do desejo, que funda uma abertura para o relacionamento com os outros, o eu se fecha sobre si mesmo, e o desejo, no lugar de se tornar abertura para os outros, torna-se desejo do não desejo, que Freud designou como tendência ao zero absoluto.

Esta tendência ao zero absoluto é a característica principal do "Princípio de Nirvana" (Nirwanaprinzip), que, por sugestão de Barbara Low, Freud introduziu na sua teoria psicanalítica, por ocasião da introdução da pulsão de morte, no contexto da reformulação da sua teoria das pulsões (Freud, 1920/1982c). No artigo sobre "O problema econômico do masoquismo" (1924), ele articulou o princípio de Nirvana com a pulsão de morte, quando esta opera como uma força de destruição silenciosa no interior do sujeito, fazendo calar o desejo de viver e mergulhando-o no vazio do não desejo.

\section{Narcisismo de morte}

Não parece estranho articular o narcisismo com a morte? Não seria mais plausível dizer que o narcisismo é o guardião da vida? Portanto, em que circunstâncias pode ele tornar-se um agente de morte e, em vez de nutrir as forças da vida por meio dos processos criativos, colocar-se a serviço das forças da morte e da destruição? Freud advertiu que uma certa dosagem de narcisismo era indispensável para a saúde humana, porque, sem ela, nenhuma autovaloração de si mesmo seria possível. Todavia, aqueles que estão fechados no seu próprio narcisismo, tornam-se seres incapazes de amar e, consequentemente, condenados a se tornarem doentes.

Quando excessivo, o narcisismo fecha o sujeito no seu próprio eu, ou no grupo ao qual o eu pertence e com o qual se identifica, sem lhe deixar possibilidade alguma de abertura para o mundo dos outros. Assim, ele se torna um "narcisismo de morte". Com efeito, o processo de constituição psíquica do eu não se realiza que pela mediação de um outro, mas de um outro que seja verdadeiramente outrem. Sem esta abertura para o outro, o narcisismo, que deveria ser uma tendência para a vida, torna-se uma tendência para a morte.

\section{A lição do mito}

Aliás esta articulação do narcisismo com a morte é uma lição do próprio Mito de Narciso, que nos foi transmitida pelo Livro III das Metamorphoses de 


\section{ARTIGOS}

Ovídio. Tendo recusado o amor das ninfas, e, particularmente, da ninfa Echo, Narciso foi condenado a uma forma impossível de amor, vale dizer, ele não poderia jamais atingir o objeto de seu amor. $\mathrm{Na}$ impossibilidade de sair de si mesmo, ele foi condenado a não poder investir sua libido num outro diferente de si, mas tão somente no outro de si mesmo, vale dizer, na sua própria imagem. Na impossibilidade de poder atingir o objeto de seu amor, ele renuncia ao desejo de viver e mergulha na noite e no vazio do não desejo. E, no lugar de seu corpo, nasceu a flor de narciso, a flor dos cultos funerários, que a literatura grega consagrou às divindades subterrâneas. Podemos, portanto, concluir que, no mito grego de Narciso, já se encontra uma profunda união do narcisismo com a morte.

\section{Pulsões a serviço da vida e da morte}

O homem, cuja essência foi definida por Aristóteles como um "zoon politikón”, um animal político de natureza racional, antes de ser definido como um "animal symbolicum" (Cassirer, 1977, p. 51), um criador de símbolos, é um ser de pulsão e de desejo, marcado pelo jogo contraditório de duas tendências constantemente em conflito: uma dinamizada pelas pulsões de vida e a outra marcada com o selo da pulsão de morte.

As forças libidinais, que estão a serviço da vida, são aquelas que nos levam, em nome do amor, a fazer deste mundo, em que estamos situados, um mundo habitável, no qual possamos encontrar a alegria de viver em harmonia conosco mesmos e em solidariedade com os outros, bem como de nos empenharmos numa luta para fazer deste um mundo mais justo e mais humano.

No entanto, em contradição com esta vontade de dizer "sim" à vida e ao amor, trazemos, dentro de nós mesmos, uma tendência destruidora que, "para além do princípio de prazer", manifesta-se como uma pulsão de morte e de destruição. A pulsão de morte trabalha tanto em silêncio, no interior de cada um de nós, como acontece no trabalho de autodestruição do melancólico, como pode também se manifestar, fora de nós, sob a forma de um grande clamor, o clamor da guerra, da violência e da destruição, que fazem do homem o mais violento dos animais, porque é o único que mata pelo prazer de matar e destrói pelo prazer de destruir.

$\mathrm{Na}$ perspectiva psicanalítica, a atitude fundamentalista define-se como a de uma pessoa narcisista. A crença e a adesão incondicionais, que estão na base da atitude fundamentalista, são de natureza narcísica, pois esta crença dogmática leva o fundamentalista a se imaginar "dono da verdade", da única verdade que salva. Ele se considera melhor do que os outros, e o fanatismo de suas crenças religiosas define também seu estilo de vida familiar e social, bem como seus valores éticos. 
O narcisismo fálico infantil, caracterizado por um estado de perfeição imaginária absoluta, está na base dos ideais, aos quais os fundamentalistas consagram suas vidas. Sem pretender excluir outras razões e motivações possíveis, ligadas às suas convicções políticas e religiosas, podemos dizer que, em última análise, é esta megalomania narcísica, característica do narcisismo fálico da infância, que leva os fundamentalistas ao fanatismo e à intransigência, bem como às atitudes loucas de morrer satisfeitos pela causa e pelo ideal que abraçaram.

Somente uma gratificação narcísica tão profunda poderia revelar a razão de tal atitude. Morrendo por seus ideais, os fundamentalistas não fazem necessariamente uma opção contra a vida, eles renunciam ao desejo de viver sobre esta terra, porque acreditam que uma nova vida os aguarda além da morte, na qual todos os seus desejos serão plenamente satisfeitos.

\section{A paixão pelos ideais}

Os fundamentalistas fazem da religião e da causa política, às quais aderem, um verdadeiro ideal diante do qual se posicionam como todo homem apaixonado, vale dizer, eles investem toda sua libido no objeto desta sua paixão. Assim investido, o objeto da paixão torna-se único e insubstituível porque, nele, encontram-se todas as perfeições possíveis e imagináveis. Com ele, o apaixonado tem tudo, e sem ele nada tem.

Como já havia observado o próprio Freud (1921/1982d), esta idealização do objeto da paixão traz consigo necessariamente um empobrecimento do eu. Todavia, o eu empobrecido logo procura e encontra satisfações compensadoras, na medida em que, por causa da natureza narcísica de seu amor, ele termina projetando seu eu no objeto idealizado de sua paixão. Dir-se-ia que ele sacrifica seu próprio eu individual em nome de um Eu ideal, que se torna o modelo de toda perfeição e a fonte de toda felicidade.

\section{O Eu Ideal}

A distinção, estabelecida por Freud, entre o Eu ideal e o Ideal do eu (Idealich und Ichideal), por ocasião da reformulação de sua teoria do psiquismo em "O ego e o id" (1923) pode ser-nos útil para melhor compreender a natureza do Ideal e das idealizações dos fundamentalistas religiosos. Esta distinção ajudar-nos-á também a melhor compreender a dimensão perversa, que marca a elaboração das idealizações e dos ideais dos fundamentalistas religiosos. 


\section{ARTIGOS}

No texto de Freud, temos, às vezes, a impressão de que o Eu ideal e o Ideal do eu são conceitos sinônimos, mas, pelo contrário, eles são conceitos muito diferentes e, entre os dois, existe a mesma distância epistemológica, que separa a ordem imaginária fantasmática, da ordem simbólica da cultura. Com efeito, o que é o Eu ideal? Ele é uma instância psíquica imaginária, forjada pela megalomania narcísica e fálica da criança. Esta, no período de seu narcisismo primário, quando seu eu não foi ainda confrontado com as exigências e os limites da realidade, mas é unicamente regido pelo princípio do prazer, projeta, sobre seu próprio eu, o ideal de perfeição, que ele imagina que as figuras onipotentes e todo-poderosas de seus pais possuem.

No contexto de seu estudo sobre a Verliebtheit (1921), Freud observa que, no decorrer da existência, o Eu ideal pode ser projetado sobre figuras substitutivas e que o objeto da paixão amorosa poderia ser um desses objetos substitutos do Eu ideal infantil. O mesmo poder-se-ia dizer dos ideais dos fundamentalistas religiosos. Dir-se-ia que, em uma tentativa ilusória, o apaixonado amoroso, bem como o fundamentalista religioso, querem recuperar o estado de plenitude psíquica e de complementaridade narcísica - o paraíso de suas infâncias - que foi para todo sempre perdido e que, realmente, jamais existiu, a não ser nas fantasias das crianças, nos sonhos dos adultos e nos mitos da Humanidade.

A doutrina religiosa e a causa política, às quais os fundamentalistas aderem incondicionalmente, são, portanto, substitutos do Eu ideal de suas infâncias. No ato de transferir ao grupo, ou ao seu líder, a atitude de admiração incondicional, o indivíduo faz, ao mesmo tempo, a experiência de uma satisfação narcísica, porque, pelo mecanismo da identificação, ele faz um só com o grupo a que pertence. Como diz Freud (1921), o indivíduo se despoja de seu Eu ideal próprio e particular para projetá-lo sobre o Eu ideal do grupo ou de seu líder.

\section{O Ideal do Eu}

De outra natureza são os ideais, que não são sustentados por uma atitude de admiração e de adesão incondicionais. Esta nova maneira de abordar a questão do ideal relaciona-se a outra instância psíquica, que Freud designou com o nome de Ideal do Ego. Este, em oposição ao Eu ideal, é uma instância psíquica que, pela sua constituição, supõe a experiência e a aceitação da "castração simbólica", pela qual o sujeito renuncia, precisamente, às ambições fálicas do Eu ideal, a fim de que lhe seja possível instalar-se no jogo das relações humanas, enquanto relações que sejam verdadeiramente intersubjetivas. É pela mediação do Ideal do Eu que o 
sujeito encontra um modelo de identificação, sem o qual ele não poderia assumir a sua posição de sujeito na ordem simbólica da linguagem.

O discurso que sustenta o Ideal do Eu não é, de modo algum, um discurso de adesão incondicional, como era aquele que sustentava o Eu ideal, mas um discurso discriminatório, vale dizer, um discurso que não enuncia uma adesão incondicional, mas que leva em consideração se o objeto escolhido como ideal satisfaz, ou não, às exigências de valor, segundo as quais os ideais são medidos.

Alguns dentre os psicanalistas dão a impressão de não distinguir esses dois registros de nossos ideais, e, às vezes, demonstram, nos seus discursos, uma certa desconfiança diante dos ideais, como se todos fossem nutridos por uma certa dose de ilusão, criada precisamente para afastar o homem da confrontação inexorável com seu estado fundamental de desamparo. Freud, ele próprio, lamentava esta situação quando assim se exprimiu: "porque destruímos as ilusões, reprovam-nos o fato de colocar em perigo os ideais" (Freud, 1910/1982a - Ergänzungsband, p. 132).

Em vez das idealizações que, como já sabemos, dominam as ilusões narcísicas do Eu ideal, o Ideal do Eu coloca em movimento outros dispositivos de investimento objetal, entre os quais destacam-se, de modo particular, o mecanismo da sublimação, o qual, por sua vez, não é nem compreensível, nem eficaz se, primeiramente, não se realiza um verdadeiro trabalho de luto das idealizações ilusórias do Eu ideal (Da Poian, 1998, pp. 133-140).

Os ideais, enquanto projetos do Ideal do $\mathrm{Eu}$, em vez de fechar o Eu numa ilusória plenitude narcísica, tornam possível, por meio da sublimação e da capacidade criativa do eu, a abertura de novos horizontes, que possibilitarão novos investimentos objetais. Sem dúvida, deve-se reconhecer que existe sempre o perigo de uma possível regressão dos projetos do Ideal do Eu às satisfações ilusórias do Eu ideal. E quando isto acontece, entra em cena a perversão dos ideais.

Freud nos advertiu a possibilidade deste perigo quando, no seu estudo "Psicologia das massas e análise do eu" (1921/1982d), articulou a paixão amorosa com a hipnose. Nos dois casos, tanto o objeto da paixão amorosa, quanto o objeto da relação hipnótica, é um substituto do Ideal do Eu que retrocede à condição de Eu ideal. E quando isto acontece, o Ideal do eu perde a sua função crítica e mergulha naquilo que Freud chamou a "cegueira do amor" - Die Liebesverblendung (p. 106).

Pois bem, é esta cegueira do amor e ausência da função crítica do Ideal do Eu que abrem para o eu o mundo da perversão, pois, como diz Freud, elas podem transformar um homem num ser sem remorsos e em um verdadeiro assassino. Por isso, dizemos que a ausência da função crítica do Ideal do Eu, juntamente com as formas ilusórias de idealização narcísica do Eu ideal, permitem que possamos falar das raízes perversas do fundamentalismo religioso. 


\section{ARTIGOS}

\section{À guisa de uma conclusão}

À guisa de uma conclusão, sim, porque não se trata de uma verdadeira conclusão. Já sabemos que a psicanálise não possui a solução definitiva do enigma do fundamentalismo religioso. Vamos, portanto, apresentar aqui, à guisa de uma conclusão, uma rápida reflexão sobre a questão da Barbárie, à qual nos referimos no começo desta nossa comunicação.

Desde a cultura helênica, existe o costume de se dizer que o bárbaro é o outro e que ele vem, sempre, de fora. O bárbaro é o inimigo. Era assim para os gregos e os romanos na Idade antiga. Era assim na Cristandade medieval. Era assim, também, em um tempo mais perto de nós, para os nazistas. Depois do dia 11 de setembro de 2001, o fundamentalista islâmico foi feito o inimigo número um da humanidade!

Mas o verdadeiro inimigo da Humanidade é a Barbárie, e esta, como observou muito bem Walter Benjamin (1985), é engendrada no ato mesmo, pelo qual é produzida a Cultura. A Barbárie é intrínseca ao movimento de criação e de transformação da Cultura humana. ${ }^{1}$

Podemos, então, concluir que o bárbaro também nos habita e se torna uma só coisa com as tendências cruéis e destruidoras que, dentro de nós, estão a serviço da morte e da destruição.

Todavia, mais forte do que a morte é o amor, e o amor também nos habita e nos sustenta na luta contra todas as formas de Barbárie, revelando-nos, a cada instante, que "a vida é bela e que merece ser cantada simplesmente porque é vida".

\section{Referências}

Benjamin, W. (1985). O conceito de história. In Obras escolhidas. São Paulo: Brasiliense.

Cassirer, E. (1977). Antropologia filosófica. Ensaio sobre o Homem. (Vicente Queiroz, trad.). São Paulo: Mestre Jou.

Chauí, M. (2006). Fundamentalismo religioso: a questão do poder teológico-político. In Filosofia Política Contemporânea. Controvérsias sobre Civilização, Império e Cidadania. Atílio A. Boron, Buenos Aires, Consejo Latinoamericano de Ciencias Sociales - CLACSO. São Paulo, Departamento de Ciência Política. Faculdade de Filosofia, Letras e Ciências Humanas. Universidade de São Paulo.

Da Poian, C. (1998). O desamparo e a questão dos ideais. Desamparo. Cadernos de Psicanálise. Círculo Psicanalítico do Rio de Janeiro, 20(12), 133-140.

${ }^{1}$ Walter, B. O conceito de história. In Obras escolhidas. São Paulo: Brasiliense, 1985. 
Freud, S. (1982a). Die zukünftigen Chance der psychoanalytischen Therapie. Studienausgabe (SA), Ergänzungsband, 132. Frankfurt am Main, Fischer Taschenbuch Verlag. Tradução brasileira - Standard Brasileira. As perspectivas futuras da terapêutica psicanalítica (Vol. XI). Rio de Janeiro: Imago. (Trabalho original publicado em 1910).

Freud, S. (1982b). Zur Einführung des Narzissmus. SA. Band III, 37-69. Tradução brasileira (SB) Sobre o Narcisismo: uma introdução (Vol. XIV). Rio de Janeiro: Imago, 1974. (Trabalho original publicado em 1914).

Freud, S. (1982c). Jenseits des Lust Prinzips. SA. Band III. 213-273. Tradução brasileira: Além do princípio do prazer. (Vol. XVIII, 1976). (Trabalho original publicado em 1920).

Freud, S. (1982d). Massenpsychologie und Ich-Analyse. SA. Ergänzungsband, p.106. Tradução brasileira (SB) A psicologia das assas e análise do ego. (Vol. XVIII, 1976, p. 197. (Trabalho original publicado em 1921).

Freud, S. (1982e) Das Ich und das Es. (SA) Band III, p. 273. Tradução Brasileira (SB) O Ego e o Id (Vol. XIX, 1976, p. 13). (Trabalho original publicado em 1923).

Freud, S. (1982f) Das Ökonomische Problem der Masochismus.. S.A. Band III, 339. Tradução Brasileira (SB) O problema econômico do masoquismo (Vol. XIX, 1976, p. 199. (Trabalho original publicado em 1924).

Green, A. (1983). Narcissisme de vie, narcissisme de mort. Paris: Les Éditions de Minuit.

Herwey, D. (1992). A condição pós-moderna. São Paulo: Loyola.

\section{Resumos}

(The perversion of the ideals on the religious fundamentalism)

The present paper discusses Freud's metapsychology in regard to certain psychic processes and components of a perverse nature that are at the basis of ideals of religious fundamentalism. It is our aim to work with the concept of "narcissism of death" (or "negative narcissism") and its articulation with the death drive, as well the distinction between the ideal ego and the ego ideal. The aim is to better understand the model of "idealizations," where religious fundamentalists sacrifice their own egos in the name of an ideal ego that is little more than a projection of their own infantile narcissistic ambitions.

Key words: Religious fundamentalism, narcissism, perversion, Ego ideal and Ideal ego

(La perversion des idéaux dans le fondamentalisme religieux)

Cet article a pour but de réfléchir, dans la perspective de la métapsychologie freudienne, sur quelques composants psychiques de nature perverse qui sont à la base des idéaux des fondamentalistes religieux. Dans ce sens, nous prenons en compte le concept de "narcissisme de mort» (ou "narcissisme négatif») et son articulation avec 


\section{ARTIGOS}

la pulsion de mort, ainsi que la distinction entre le Moi idéal et l'Idéal du Moi pour mieux comprendre le modèle des «idéalisations» selon lesquelles les fondamentalistes religieux sacrifient leur propre moi au nom d'un Moi Idéal qui n'est rien d'autre que la projection de leurs ambitions narcissiques enfantines.

Mots clés: Fondamentalisme religieux, narcissisme, perversion, Moi idéal et Idéal du Moi

(La perversión de los ideales en el fundamentalismo religioso)

El presente ensayo busca reflexionar, en la perspectiva de la metapsicología freudiana, sobre algunos de los componentes psíquicos de naturaleza perversa, que están en la base de los ideales de los fundamentalistas religiosos. Es nuestro propósito trabajar los conceptos de "narcisismo de muerte" ("narcisismo negativo") y su articulación con el instinto de muerte, como también la distinción entre Yo ideal e Ideal del Yo para una mejor comprensión del modelo de las "idealizaciones" por las cuales los fundamentalistas religiosos sacrifican su propio Yo, en nombre de uno Yo Ideal que no es otra cosa sino la proyección de sus ambiciones narcisistas infantiles.

Palabras claves: Fundamentalismo religioso, metapsicología freudiana, narcisismo, Yo Ideal e Ideal del Yo

(Die perversion der Ideale im religiösen Fundamentalismus)

Ziel dieses Beitrags ist es, aus der Perspektive der freudschen Metapsychologie, über einige perverse psychische Vorgänge und Komponente nachzudenken, die den Idealen der religiösen Fundamentalisten zugrunde liegen. In diesem Zusammenhang werden wir den Begriff „Narzissmus des Todes" (oder "negativer Narzissmus"), sowie sein Zusammenspiel mit dem Todestrieb und die Unterscheidung zwischen dem idealen Ich und dem Ich-Ideal in Betracht ziehen. Dies soll helfen, das Modell der „Idealisierungen" besser zu verstehen, durch die die religiösen Fundamentalisten ihr eigenes Ich im Namen eines idealen Ichs opfern, welches nichts anderes als die Projektion der eigenen kindlichen, narzisstischen Begehren ist.

Schlüsselwörter: Religiöser Fundamentalismus, Perversion, Narzissmus, Ideal-Ich, Ich-Ideal

Citação/Citation: Rocha, Z. (2014, setembro). A perversão dos ideais no fundamentalismo religioso. Revista Latinoamericana de Psicopatologia Fundamental, 17(3-Suppl.), 761-774.

Editor do artigo/Editor: Prof. Dr. Manoel Tosta Berlinck

Recebido/Received: 15.3.2014/ 3.15.2014 Aceito/Accepted: 15.4.2014 / 4.15.2014

Rev. Latinoam. Psicopat. Fund., São Paulo, 17(3-Suppl.), 761-774, set. 2014 
Copyright: (C) 2009 Associação Universitária de Pesquisa em Psicopatologia Fundamental/ University Association for Research in Fundamental Psychopathology. Este é um artigo de livre acesso, que permite uso irrestrito, distribuição e reprodução em qualquer meio, desde que o autor e a fonte sejam citados / This is an open-access article, which permits unrestricted use, distribution, and reproduction in any medium, provided the original author and source are credited.

Financiamento/Funding: $\mathrm{O}$ autor declara não ter sido financiado ou apoiado / The author have no support or funding to report.

Conflito de interesses/Conflict of interest: $\mathrm{O}$ autor declara que não há conflito de interesses / The author has no conflict of interest to declare.

\section{ZEFERINO ROCHA}

Mestre em Filosofia e Teologia pela Pontificia Universidade Gregoriana de Roma (19481952); Doutor em Psicologia pela Universidade de Paris-X (1973); Prof. do Programa de Pós-Graduação (Mestrado e Doutorado) em Psicologia Clínica da Universidade Católica de Pernambuco - Unicap (Recife, PE, Br).

Rua Conselheiro Portela, 139/502

52020-212 Recife, PE, Br.

e-mail: zephyrinus@globo.com 